ORIGINAL ARTICLE

\title{
Predictors and severity of injury in assaults with barglasses and bottles
}

\section{K S Coomaraswamy, J P Shepherd}

Injury Prevention 2003;9:81-84

Background: Although glasses and bottles are frequently used as weapons in assaults, there is little knowledge on which prevention strategies can be based.

Design: Scrutiny of a random sample of 1288 criminal injury compensation applications.

Objective: To identify predictors and relative severity of glass and bottle injury.

Method: Injury site, severity, treatment, and demographic characteristics of victims and assailants were studied with reference to awards from the UK national Criminal Injuries Compensation Authority (CICA).

Main outcome measures: Gender of victims and assailants, injury sites, treatment, and award (UK pounds) as indices of injury severity.

Results: Annual CICA awards to all victims of assaults in licensed premises during 1996-98 amounted to $£ 4.08$ million (for all glass/bottle assaults: $£ 1.15$ million $=28 \%$ ). The mean cost of 746 glass assaults was $£ 2347$, compared with $£ 2007$ for 542 injuries from bottle assaults (mean difference $£ 340 ; p<0.01$ ). This difference largely reflected more eye injuries with glasses ( 26 cases: $3 \%$ of all glass assaults) than with bottles (eight cases: $1 \%$ of all bottle assaults).

Bottle assault was significantly associated with unidentified assailants and scalp injuries; whereas See end of article for
authors' affiliations

Correspondence to: Professor Jonathan Shepherd, Violence Research Group,

Department of Oral

Surgery, Medicine and

Pathology, University

Dental Hospital and

School, Heath Park, Cardiff

CF14 4XY, UK

shepherdjp@cardiff.ac.uk glass injury was significantly linked to pub opening hours (midday to midnight), Thursdays, eye and face injuries, and treatment requiring sutures.

Mean age of bottle assault victims (26.1 years) was lower than of glass victims (27.3 years; $\mathrm{p}<0.01$ ), and same gender assaults were more frequent than between gender assaults for both bottle $(p<0.001)$ and glass $(p<0.001)$ assaults. Female victims were allocated to lower compensation awards more frequently than male victims; this was the case for both bottle $(p<0.05)$ and glass $(p<0.01)$ assaults.

Conclusions: Assaults with bottles caused less serious injury and resulted in lower compensation costs. Injury distribution was linked to victim gender and weapon choice, but not to assailant gender. Prevention strategies should focus on both bottle and glass assaults and should take account of the setting and time in which drinking occurs.
$\mathrm{V}$ olence has become a significant public health issue in many countries. Although internationally, firearms assaults attract more media attention, interpersonal violence involving other weapons are more commonplace. In the UK, very low rates of police recording of violent offences which result in hospital treatment ${ }^{1}$ and assaults with bar glassware have been a major focus of attention. ${ }^{23}$ Only about one quarter of all assaults and only about one in nine assaults in licensed premises leading to accident and emergency department treatment have been recorded by the police. ${ }^{4}$ Until about 1990, it was not recognised that bar glassware was the most frequently used sharp weapon in assaults. ${ }^{56}$ Glasses and bottles are used as weapons in about $10 \%$ of all assaults which result in treatment in UK emergency units. ${ }^{7}$ Furthermore, bar glassware has been identified as the principal weapon in licensed premises violence. ${ }^{7}$ Most of these result in long term noticeable facial disfigurement. Subsequently, the types of glassware most often selected as a weapon and the risk reduction possible through the use of toughened glassware have been identified. ${ }^{8}$ These findings have led to the progressive adoption of toughened glass in the UK licensed trade: in response to demand, and availability of toughened glass from French manufacturers, both UK barglass manufacturers switched to toughened glass production.

Increased use of bottled drinks in bars and continued concentration of assaults in and around bars and clubs means, however, that it is important to understand the circumstances of assaults in which glassware is used as a weapon and the relative severity/outcome of these assaults. It is only on this basis that targeted prevention strategies can be determined. This information is not available. This study focuses on glass injury because previous epidemiological studies have demonstrated that it is, apart from assaults where no weapons other than body parts like fists and feet are used, the most frequently used weapon category in licensed premises-which are known to be a focus for violence.

In the UK, the Criminal Injuries Compensation Authority (CICA), under the governance of its sponsor department, the Home Office, is responsible for assessing cases and dispensing compensation to those injured in violent crime. The CICA originated in 1964 as a government ex gratia scheme (that is, non-statutory). It was then the Criminal Injuries Compensation Board (CICB), comprising lawyers who appraised each case and allocated a suitable award. However, because the awards made by the CICB were relatively subjective and administratively costly, the Criminal Injuries Compensation Act was introduced in November 1995, which facilitated the introduction of a revised tariff (banded) scheme, which came into effect on 1 April 1996. Successful applicants must have

Abbreviations: CICA, Criminal Injuries Compensation Authority; CICB, Criminal Injuries Compensation Board

*Exchange rates: $£ 100$ (UK pounds) $=€ 159$ (euros) = US\$157 (dollars). 


\begin{tabular}{|c|c|c|c|c|c|c|}
\hline 152068 & \multicolumn{6}{|c|}{ Applications relating to all assaults (received 1 April 1996 to 31 March 1998) } \\
\hline & 15217 & \multicolumn{5}{|c|}{ Assaults in licensed premises } \\
\hline & & 11511 & \multicolumn{4}{|c|}{$\begin{array}{l}\text { Assaults in licensed premises involving injuries } \\
\text { caused by weapons other than bar glassware }\end{array}$} \\
\hline & & 3706 & \multicolumn{4}{|c|}{$\begin{array}{l}\text { Assaults in licensed premises involving injuries } \\
\text { caused by bar glassware }\end{array}$} \\
\hline & & & 1432 & \multicolumn{3}{|c|}{$\begin{array}{l}\text { Sample of } 40 \% \text { of bar glassware } \\
\text { assaults in licensed premises }\end{array}$} \\
\hline & & & & 144 & Exclusions: & \\
\hline & & & & & 6 "Nil awards" & $\begin{array}{l}1 \text { bottle, } \\
5 \text { glass }\end{array}$ \\
\hline & & & & & $\begin{array}{l}54 \text { Non-licensed } \\
\text { premises }\end{array}$ & $\begin{array}{l}29 \text { bottle, } \\
25 \text { glass }\end{array}$ \\
\hline & & & & & \multicolumn{2}{|c|}{84 Mixed weapon assaults } \\
\hline & & & & 1288 & \multicolumn{2}{|l|}{ Admissible cases } \\
\hline & & & & & \multicolumn{2}{|c|}{542 Assaults with bottles } \\
\hline & & & & & \multicolumn{2}{|c|}{746 Assaults with glasses } \\
\hline
\end{tabular}

Figure 1 ClCA applications received and sampled for the period investigated.

been physically or mentally injured. ${ }^{9}$ Injuries need to be serious enough to qualify for a minimum award (currently $\left.£ 1000^{*}\right)$ and the incident must have been reported to the police.

Upon receipt of an application, cases are assessed for eligibility and validity. Injuries sustained, loss of earnings if out of work for more than 28 weeks after the injury and expenses are all taken into account. Injuries are assessed according to a tariff of injuries (330 injury descriptions organised into 25 award levels ranging from $£ 1000$ to $£ 250000)$; and in the case of multiple injuries, $10 \%$ of the second highest rated and $5 \%$ of the third highest rated injuries are added to the full amount of the main (highest rated) injury.

The overall tariff limit is currently $£ 500$ 000. Reductions in awards may be made on the grounds of the victim's character, taking into account previous criminal convictions, conduct before, during or after the assault leading to injury, level of cooperation with the police, and awards or compensation already received. It should be noted that criminal injury compensation only represents the response of the state (society) to victimisation and that compensation takes no account of other costs, for example costs related to dealing with offenders.

\section{SUBJECTS AND METHODS}

In this study, it was hypothesised that victim and assailant gender, time of day, and day of week might predict differences between bottle and glass injury and that particular injury site(s) and treatment might be associated more with glass or bottle injury. This approach stemmed from previous findings of gender differences in weapon selection and gender specific injury patterns. In particular, a lower incidence of facial injuries in female victims has been found compared with males, ${ }^{4-6}$ and there is evidence that the area of the face targeted by males in assaults on males and females differs. For example, males seem to target the nose in blunt assaults on females much less commonly than in assaults on males. This provides evidence of at least some target selection, despite the intoxication of most assailants. ${ }^{5}$

The case files of the CICA are all in a standard format and contain more detailed information on the victims and assaults in question than any other source available. These files relate only to a small proportion of all community assaults during the study period. Many assault victims do not apply for compensation to the CICA because they are not prepared to report to the police, they cannot identify their assailant, are fearful of reprisals, or have a continuing relationship with their assailant(s).
For convenience, hours of the day were subdivided into four six hour blocks reflecting the morning (0600-1159 hours), afternoon (1200-1759 hours), pub peak hours ("pub time"; 1800-2359 hours), and nightclub peak hours ("clubtime"; 0000-0559 hours). Many assaults that occurred after midnight were associated with the previous evening. Thus all assaults that took place up to 0559 hours were classified as occurring on the previous day.

Altogether 3706 applications relating to assaults with bar glassware in licensed premises (fig 1) were identified from a computer search of all 152068 case files relating to applications received by the CICA in the two years after the introduction of the tariff scheme (1996-98). During the same period, 11511 applications were received which related to assaults associated with licensed premises in which injury had been caused by other weapons (including body parts: mainly fists and feet).

A random sample of 1432 (40\%) applications was identified and data transcribed manually from each file over several visits by one of the authors (KC) to the CICA between 1998 and 2000. However, only 1288 applications satisfied the criteria of the study. Of the 144 cases excluded, six (one bottle, five glass) were allocated a "nil award", 54 (29 bottle, 25 glass) were excluded because assaults occurred elsewhere than in or near licensed premises, and the remaining 84 cases were excluded because injuries had reportedly been caused by a combination of weapons. Information was collated about assault date, assault time, weapon used, injury sites, treatment received, award band, and amount awarded in the first two years after the introduction of the tariff scheme on 1 April 1996 in relation to assaults in or near UK licensed premises in which glasses or bottles had been used as weapons.

Student's $t$ test was used for the comparison of mean compensation awards, and the $\chi^{2}$ test for examining univariate associations between different pairs of predictors for the two weapons. Logistic regression was applied to interrelate the investigated predictors (hypothesised to affect the outcome variable) in a statistical model and explore the significance of their relationship to the assault weapon.

\section{RESULTS}

In the two years of the study, the CICA paid a total of $£ 410823435$ in compensation. Assaults in licensed premises led to a total payout in the two years of $£ 8153804$. Out of a total of 152068 applications, 3706 were received from people injured in assaults in licensed premises in which glassware had been used as a weapon. Compensation awards to these 
Table 1 CICA compensation awards for bottle and glass injuries adjusted for eye injuries

\begin{tabular}{|c|c|c|c|c|c|c|c|c|}
\hline Weapon & Eye injuries & Cases & Mean (SD) (£) & $95 \% \mathrm{Cl}$ & Difference (£) & Difference (\%) & $p$ Value & $95 \% \mathrm{Cl}$ \\
\hline Bottle & Included & 542 & $2007 *(1383)$ & 1891 to 2124 & & & & \\
\hline Glass & Included & 746 & 2347 * $(2433)$ & 2172 to 2521 & 340 & 16.9 & 0.002 & 129 to 549 \\
\hline Bottle & Excluded & 534 & 1999 * (1384) & 1882 to 2117 & & & & \\
\hline Glass & Excluded & 720 & $2111 *(1279)$ & 2017 to 2204 & 112 & 5.6 & 0.145 & -38 to 261 \\
\hline
\end{tabular}

applicants totalling $£ 2302630$ ( $£ 1151315$ per year) were made $(0.6 \%$ of the total CICA payout for the period). Not all applicants were successful however.

Of the 1288 cases included in the study, 542 related to assaults with bottles and 746 to assaults with glasses. Mean CICA awards for both bottles and glasses are set out in table 1 . Because it appeared that differential rates of eye injury in the two groups of claimants might explain differential mean awards, awards are shown for injuries including and excluding eye injuries. Mean compensation for bottle injury was $£ 2007$ and for glass injury was $£ 2347$. Mean awards for injuries caused by glasses were $£ 340$ (16.9\%), more than for injuries inflicted with bottles $(\mathrm{p}<0.01)$.

Awards for injuries sustained in assaults with glasses were three times more likely to include compensation for eye injuries than awards for injuries sustained in assaults with bottles. This was also confirmed from logistic regression, where it was found that glass injuries were more than twice as likely to involve the eye than bottle injuries $(\mathrm{p}<0.05)$. In all, 26 awards for assaults with glasses included compensation for eye injury (eight awards for assaults with bottles). When cases with eye injuries were excluded, the difference was $£ 112$ (5.6\%), which was not statistically significant.

Table 2 Logistic regression model for assaults involving barglassware in UK licensed premises

\begin{tabular}{|c|c|c|c|}
\hline Variable & Odds ratio & $95 \% \mathrm{Cl}$ & $\mathrm{p}$ Value \\
\hline \multicolumn{4}{|l|}{ Victim gender } \\
\hline Male (ref) & 1.00 & ref & - \\
\hline Female & 0.92 & 0.65 to 1.31 & 0.67 \\
\hline \multicolumn{4}{|l|}{ Assailant gender } \\
\hline Male (ref) & 1.00 & ref & - \\
\hline Female & 1.30 & 0.87 to 1.98 & 0.20 \\
\hline Unknown & 0.56 & 0.35 to 0.87 & 0.01 * \\
\hline \multicolumn{4}{|l|}{ Time period } \\
\hline Morning & 2.23 & 0.22 to 22.05 & 0.49 \\
\hline Afternoon & 4.33 & 2.23 to 8.47 & $0.00 *$ \\
\hline Pubtime & 2.38 & 1.85 to 3.08 & $0.00^{*}$ \\
\hline Clubtime (ref) & 1.00 & ref & - \\
\hline \multicolumn{4}{|l|}{ Day } \\
\hline Monday (ref) & 1.00 & ref & - \\
\hline Tuesday & 1.49 & 0.69 to 3.20 & 0.30 \\
\hline Wednesday & 1.17 & 0.56 to 2.47 & 0.68 \\
\hline Thursday & 2.20 & 1.13 to 4.29 & $0.02 *$ \\
\hline Friday & 1.30 & 0.72 to 2.33 & 0.38 \\
\hline Saturday & 1.06 & 0.60 to 1.87 & 0.85 \\
\hline Sunday & 1.34 & 0.71 to 2.50 & 0.37 \\
\hline \multicolumn{4}{|l|}{ Injury sitet } \\
\hline Scalp & 0.25 & 0.19 to 0.37 & $0.00 *$ \\
\hline Face & 1.14 & 0.75 to 1.72 & 0.53 \\
\hline Neck & 1.17 & 0.75 to 1.84 & 0.48 \\
\hline Eye & 2.64 & 1.09 to 6.37 & $0.03 *$ \\
\hline Hand & 0.89 & 0.53 to 1.52 & 0.68 \\
\hline Other & 0.77 & 0.56 to 1.06 & 0.11 \\
\hline \multicolumn{4}{|c|}{ Treatment requiredt } \\
\hline Dressing & 1.13 & 0.76 to 1.67 & 0.53 \\
\hline Sutures & 1.82 & 1.16 to 2.86 & 0.01 * \\
\hline Admitted & 0.74 & 0.38 to 1.43 & 0.37 \\
\hline Other & 0.77 & 0.47 to 1.26 & 0.30 \\
\hline
\end{tabular}

$\mathrm{Cl}$, confidence interval. * Statistically significant. $\mathrm{T}$ No reference category as not single variables.
Although eye injuries accounted for most of the variance between mean compensation awards for bottle and glass injuries, additional analyses were undertaken in search for further significant associations.

Mean age of applicants was slightly lower (26.1 years, range $15-58)$ for those injured with bottles than with glasses $(27.3$ years, range $1-70 ; p<0.01)$. The $\chi^{2}$ test did not detect a significant association between assault weapon and the gender of the victim $\left(\chi^{2}=0.34, \mathrm{df}=1, \mathrm{p}>0.05\right)$ or gender of the assailant $\left(\chi^{2}=1.79\right.$, df $\left.=2, p>0.05\right)$. However the logistic regression model indicated that it was almost twice as likely for a bottle injury to be caused by an unknown and unidentifiable assailant than it would for a glass injury $(p<0.05)$; see table 2. A significant association between victim and assailant gender was found. Significantly more women than expected inflicted injury on other women, fewer women inflicted injury on men, and fewer men inflicted injury on women than would be expected by chance; for assaults with bottles $\left(\chi^{2}=223.3, \mathrm{df}\right.$ $=2, \mathrm{p}<0.001)$ and glasses $\left(\chi^{2}=229.7, \mathrm{df}=2, \mathrm{p}<0.001\right)$.

Significantly more bottle injuries and significantly fewer glass injuries involved the scalp, and fewer bottle injuries involved the face than would be expected by chance $\left(\chi^{2}=\right.$ $82.8, \mathrm{df}=5, \mathrm{p}<0.001)$. This was reflected in the model where a bottle injury was four times as likely to involve the scalp than a glass injury $(\mathrm{p}<0.001)$.

Furthermore, more bottle injuries than expected and fewer glass injuries required "no treatment" $\left(\chi^{2}=15.794, \mathrm{df}=4\right.$, $\mathrm{p}<0.01)$. The model indicated that glass injuries were almost twice as likely to require suturing as bottle injuries $(\mathrm{p}<0.01)$. In assaults with bottles, fewer scalp and neck injuries and more injuries of other sites were seen in female victims $\left(\chi^{2}=\right.$ $24.6, \mathrm{df}=5, \mathrm{p}<0.05)$. Significantly fewer scalp injuries and more injuries of other sites were also found in female glass assault victims $\left(\chi^{2}=11.5, \mathrm{df}=5, \mathrm{p}<0.05\right)$. However there were no significant associations between gender of assailant and injury site, either in assaults with bottles $\left(\chi^{2}=7.8, \mathrm{df}=\right.$ $5, \mathrm{p}>0.05)$ or glasses $\left(\chi^{2}=6.1, \mathrm{df}=5, \mathrm{p}>0.05\right)$.

There was a significant association between victim gender and award band, reflecting less face injury in women. More serious injuries were sustained by males than females-both in assaults with bottles $\left(\chi^{2}=25.4\right.$, df $\left.=13, \mathrm{p}<0.05\right)$ and glasses $\left(\chi^{2}=56.2, \mathrm{df}=13, \mathrm{p}<0.001\right)$. The gender of the assailant and the award bands allocated showed a similar association for assaults with glasses $\left(\chi^{2}=28.1, \mathrm{df}=13\right.$, $\mathrm{p}<0.01$ ); female assailants caused more injuries of lower compensation value and male assailants caused more injuries of higher compensation value. However this association was not found for assaults with bottles $\left(\chi^{2}=14.0, \mathrm{df}=13\right.$, $\mathrm{p}>0.05$ ).

\section{DISCUSSION}

The principal finding of this research is that injuries inflicted with glass were more serious (and costly to the taxpayer) than injuries sustained by bottles. The lower compensation awards for injury from bottles compared with injury from glasses reflected lower proportions of eye injuries and also, to an extent, fewer facial injuries and injuries requiring treatment.

Strengths of this study include access to a new source of quantitative data relevant to severity of assault injury, its 
national focus and relevance to prevention. Limitations include availability of data only for two years-which means that no conclusions on trends were possible, and the fact that compensation only represents one dimension of the total costs of assault to victims, offenders, health services, and to communities

The lower mean age of assault victims of assaults with bottles compared with assaults with glasses may reflect the younger consumer group associated with "alco-pops" and other bottled alcoholic drinks. Gender differences in terms of injuries sustained and inflicted are consistent with previous research: targets in assaults are less likely to include the face and more likely to include the trunk if the victim is female. ${ }^{5}$ Conversely, the face is more often targeted in assaults on men, which therefore attract higher awards than assaults on women.

Moreover, the finding that the gender of the assailant in a bottle assault is more likely to be unknown than for a glass assault, and the finding that bottle assaults were more likely to involve the scalp and neck, and less likely to involve the face suggest the nature of most bottle attacks-a blow to the head, usually within a crowd to reduce the chances of identification. Bottle design allows their use as a club, in contrast to glass design.

The findings of this research infer that any trend towards bottled drinks in licensed premises may bring with it a lower incidence of eye and facial injury; and thus a lower severity and cost of glassware assaults to the tax payer.

However, as bottles and glasses are in widespread use in licensed premises, prevention of all glassware injuries is an urgent priority; through such initiatives as replacing glass with plastic bottles-which would lead to a substantial reduction in injury and costs-and more widespread adoption of plastic or toughened (tempered) glassware. A randomised controlled trial has demonstrated that increasing the impact resistance of glasses is associated with decreased injury risk. ${ }^{10}$ This suggests that an important objective for injury prevention should be to decrease the chances of glass breakage by all possible means: through substitution or lamination with nonbreakable materials, and through altering glass properties and thickness.

In addition, although the glass randomised controlled trial cited above found that glass which had been subject to a toughening process could result in less impact resistant glasses if the process was not carefully controlled, its recommendations on this issue have yet to be implemented. In particular, the randomised controlled trial report called for the development of manufacturing glass impact resistance standards to be developed by the British Standards Institution to protect customers and bar staff. Although the subject of a motion signed by 60 members of the UK House of Commons, this and a switch from glass to plastic bottles have yet to be taken up.

Although there has been a switch from annealed (nontoughened) to toughened half and one pint capacity beer glasses in the UK, CICA records included no information on precisely which type of glass had been used as a weapon. This level of detail was not expected, however, as the injured would not know details of glass manufacture and could not be expected to have noticed manufacturers' marks incorporated usually into the base of these glasses. This should be the subject of future research as the randomised controlled trial focused predominantly on accidental injuries. Interestingly, this study did not find evidence of blunt brain injuries-only of lacerations associated with glass breakage. This is further evidence that, as far as glass weapons are concerned, the objective should be to prevent breakage. Theoretically, achiev-

\section{Key points}

- Glass injuries were significantly more serious than bottle injuries and cost the tax payer more in compensation awards.

- The reason for this cost differential was that glasses produced more eye and facial injuries than bottles; bottle related injuries were also less likely to require treatment.

- There was a significant difference in the circumstances of bottle and glass injury.

- Prevention should focus on modification of the properties of both bottles and glasses, and target the circumstances in which these assaults occur.

- There are persuasive arguments for requiring the alcohol industry to contribute to the costs of criminal injury compensation for assaults within licensed premises.

ing this simply by increasing the bulk of glass might increase the risk of concussion. The toughening (tempering) process, of course, does not increase bulk since it is carried out after the glass has been formed. Furthermore, plastic materials are lighter than glass and therefore can confer injury reduction both through reducing breakage/fragment sharpness and also through weight reduction.

Drinks continue to be sold in glass bottles, many of which are used as weapons, when suitable and much safer alternatives-plastic bottles-are available. Overall, compensation awards from the public purse to victims injured in only one setting-licensed premises-are substantial and very largely preventable. Therefore, it can be argued that the alcohol industry-particularly licensed premises managementshould compensate the public purse for all or a proportion of this expenditure. This step would of course, provide a powerful incentive to prevent violence.

\section{ACKNOWLEDGEMENTS}

We thank the Criminal Injuries Compensation Authority for permission to scrutinise their records and Dr Kerry Hood, Department of Medical Statistics, University of Wales College of Medicine, for statistical advice.

\section{Authors' affiliations}

K S Coomaraswamy, J P Shepherd, Violence Research Group, University of Wales, College of Medicine, Cardiff

\section{REFERENCES}

1 Clarkson C, Cretney A, Davis G, et al. Assaults: the relationship between seriousness, criminalisation and punishment. Crim Law Rev 1994;July:4-20.

2 Shepherd JP. Preventing injuries from barglasses. BM 1994;308:932.

3 Shepherd JP. The circumstances and prevention of bar-glass injury. Addiction 1998:93:5-7.

4 Shepherd JP, Shapland M, Scully C. Recording of violent offences by the police: an accident and emergency department perspective. Med Sci Law 1989;29:251-5.

5 Shepherd JP, Al-Kotany MY, Subadan C, et al. Assault and facial soft tissue injuries. Br J Plastic Surg 1987;40:614-19.

6 Shepherd JP, Shapland M, Pearce NX, et al. Pattern, severity and aetiology of injury in victims of assault. J R Soc Med 1990;83:75-80.

7 Hocking MA. Assaults in Southeast London. J R Soc Med 1989:82:281-4.

8 Shepherd JP, Huggett RH, Kidner G. Impact resistance of barglasses. J Trauma 1993;35:935-8.

9 Criminal Injuries Compensation Authority. Annual report 1996/97. Edinburgh: HMSO, 1998.

10 Warburton AL, Shepherd JP. Effectiveness of toughened glassware in terms of reducing injury in bars: a randomised controlled trial. Inj Prev $2000 ; 6: 36-40$

11 Morgan J, Barnes H, Cable V, et al. Prevention of glass injuries in pubs and clubs. Early Day Motion 245. Hansard. London: House of Commons, 24 January 2001 (194.60.40.27/edmdata/html/ printable. html/ref=245). 